\title{
ORGANIZATIONAL FACTORS IMPACTING JOB STRAIN AND MENTAL QUALITY OF LIFE IN EMERGENCY AND CRITICAL CARE UNITS
}

\author{
GAUTHIER BELLAGAMBA ${ }^{1,2}$, GUILLAUME GIONTA' ${ }^{1}$, JULIE SENERGUE ${ }^{1}$, CHRISTINE BÈQUE ${ }^{1}$, \\ and MARIE-PASCALE LEHUCHER-MICHEL ${ }^{1,2}$
}

${ }^{1}$ APHM, Groupe Hospitalier Timone, Marseille, France

Occupational Medicine and Health Department

${ }^{2}$ Aix Marseille University, SPMC EA3279, Marseille, France

\begin{abstract}
Objectives: This study measures the association between hospital staff's job strain (JS), mental quality of life (MQL) and how they are influenced by the organization models within emergency and critical care units. Material and Methods: This study describes workers employed in emergency departments and intensive care units of a French public hospital. A selfadministered questionnaire was used to survey the demographic and organizational characteristics of their work, as well as work-related mental stress, psychosocial and organizational constraints, and their MQL. Results: Among 145 workers participating in the study, 59.3\% of them report job strain and 54.5\% of them have low MQL scores. The majority of staff with job strain has reported working more than 2 weekends per month, were regularly on-call, worked in dysfunctional environments and did not participate in regular meetings. The staff with low MQL worked more frequently in dysfunctional environments, had significant complaints regarding employer's efforts to promote communications or provide adequate staffing levels than the workers with a high MQL score. Conclusions: If stress reduction and improved MQL in emergency and intensive care units is to be achieved, hospital management needs to design work schedules that provide a better balance between working and non-working hours. Additionally, ergonomic design, functional environments and improved communications needs to be implemented.
\end{abstract}

Key words:

Healthcare worker, Job strain, Mental quality of life, Emergency, Intensive care units

\section{INTRODUCTION}

Several studies have shown that job strain (JS), a major component of work stress [1], effects staff's physical and mental health [2,3]. Stress-related numerous and harmful consequences include a high rate of sick leave, absenteeism [4], large turnover [5], and degradation of productivity and social climate. The cost of occupational stress was evaluated at 42 billion dollars in the United States in 2001 [6]; 14.81 billion dollars in Australia in 2008 [7]; and 2-3 billion euros in France in 2007 [8].

The hospital work environment generates high levels of staff stress $[9,10]$. Staff is more likely to develop depression [11] with doctors and nurses ranking the highest $[12,13]$. Among various services within health-care facilities, emergency and intensive care units are possibly the most stressful [14,15]. According to a British study [16], 1 out

Received: November 19, 2013. Accepted: September 28, 2014.

Corresponding author: M.-P. Lehucher-Michel, APHM, Groupe Hospitalier Timone, Occupational Medicine and Health Department, 13385, Marseille, France (e-mail: marie-pascale.lehucher@ap-hm.fr). 
of 3 intensive care staff members claims to be stressed by their work and $10 \%$ reported depressive symptoms. Two recent studies have shown that $1 / 3$ of intensive care nurses [17] and $82 \%$ of emergency room nurses [18] suffer from burnout syndrome. According to a study of 55 French hospitals [19], 13.7\% of emergency room staff and $12.9 \%$ of intensive care staff plan to leave the profession.

Emergency and intensive care units are subject to high stress levels as a consequence of managing precarious, difficult and uncertain medical situations, rapid decisionmaking, complex procedures, and considerable technical demands [14]. Previous studies have demonstrated an association between organizational factors such as a high number of hours worked, bad amount of overlap time, staff layoff, beds closed and switch to part-time and high psychosocial risks such as job stress, job dissatisfaction, job insecurity [20-22].

Many studies have assessed the JS and the quality of life of medical caregivers. To our knowledge, few of them have evaluated organizational factors that might influence these conditions. Our study's objective has been to measure the association between the JS, mental quality of life (MQL) and how the organizational factors of emergency and critical units influence staff. The hypothesis has been that an inadequate work organization is associated with the JS and low MQL.

\section{MATERIAL AND METHODS}

\section{Study design and population}

This descriptive cross-sectional study took place in a public referral university hospital in the south of France between April and January 2012 under the direction of the Occupational Medicine Department. Participants included physicians, registered nurses, health care assistants and other allied groups (physiotherapists, dieticians). Each of them had consented to the study, received a questionnaire and all of them had had at least 1 year's work experience in the selected units.

\section{Design of the self-administrated questionnaire}

The self-administrated questionnaire was divided into 4 parts:

- Part I - consisted of 51 items which explored personal, professional and organizational characteristics. These items were drawn from a sampling of hospital staff during semi-structured interviews. The interviews were conducted by a psychologist on 22 workers according to 3 confusing factors: gender, age group (under and over 40 years old) and occupational category (medical, paramedical and administrative/technical). Interviews focused on a job, department organization, working environment and a career plan. The content of the interviews was analyzed using a grid of pre-identified topics and then reviewed by 10 hospital staff members to ensure clarity and consistency.

- Part II - contained 22 items which were validated in French by the Nursing Work Index-Extended Organization (NWI-EO). These items focused on 8 psycho-organizational constraints characterizing the work environment of nurses and caregivers. These were: organizations which favored communication between unit workers; support from the senior nurse; adequate staffing to allow the work to be carried out; good relationships among unit workers; frequency of interruptions during tasks, shared values about work among the unit members; support from the administration; and respect of planned days off and vacations. Internal consistency (Cronbach's $\alpha$ coefficients were higher than 0.65 , except for 1 dimension) and testretest were satisfactory. The stability of the factorial structure was confirmed and concurrent validity was also observed [23]. Some items were tailored to be appropriate for physicians and allied personnel.

- Part III - had 26 items: the Karasek Job Content Questionnaire (JCQ) was used to assess the mental constraints associated with the job's psychological demands, decision latitude and social support [24]. Internal consistency (Cronbach's $\alpha$ coefficients were higher 
than 0.65$)$ was satisfactory. The confirmatory factor analysis showed that the best model was composed of 3 dimensions and convergent validity tests confirmed the expected association with key variables such as age, work status, a sector of activity, occupation [25].

- Part IV - had 6 items measuring the quality of life related to mental health (mental component summary - MCS). These 6 items came from the SF- $12^{\circledR}$ (Health Survey Scoring Demonstration) which is an abbreviated version of the SF-36. The higher the reported score, the better the quality of life. The correlations between the SF-36 and the SF-12 summary measures were very high (0.94-0.97) and mean 36-item summary measures and comparable 12-item summary measures were within 0.0 to 1.5 points (median $=0.5$ points) in each country and were comparable across age groups [26].

\section{Data collection}

The self-administrated questionnaire and a newsletter were sent to each participant between June and September 2011. Each subject was assigned to an anonymous number and given 30 min during their work schedule to complete the form. The participants' supervisors were informed by mail of the survey details before the start of the study.

The responsible physician collected all questionnaires in each department. Four reminders were sent between September 2011 and January 2012 by e-mail, phone call or directly to the participant at their workplace.

Participation was voluntary and anonymous, in accordance with the law of 6 August 2004. This study was approved by the National Commission for Data Protection (CNIL; No. of declaration: 1488513v0).

\section{Data analysis procedure}

A descriptive statistical analysis was performed by means of the Statistical Package for the Social Sciences (SPSS) version 20. Quantitative variables were described using mean and standard deviations, and qualitative variables were described in terms of percentage. Each aspect of the psycho-organizational constraints had a score ranging from 0 to 15 , with the highest score corresponding to the greatest constraints. As far as mental work constraints are concerned, the combination of high job demands (JD > 20) and low job control (JC < 71) was consistent with the situation about the JS [27]. To describe the level of the MQL, the average score of the French population of the MCS (47.2) was used [28]. Above or below the average score is respectively considered as a high or low MQL.

Correlations between qualitative variables were established by the Pearson's $\mathrm{Chi}^{2}$ test. Correlations between qualitative and quantitative variables were determined by a Student's t-test. In order to highlight organizational factors related to the JS or a low MQL, a logistic regression, which is a multivariate model, was conducted with the introduction of confusing factors. Confusing factors were identified in the correlation analysis with a threshold of $p<0.2$ and were reported in the tables of resulting figures. The multivariate model aimed to increase the comparability between groups by canceling the effect of confusing factors that influence both the dependent variable (i.e., the job strain and MQL) and explanatory variables (i.e., organizational factors). The adjusted odds ratio $\left(\mathrm{OR}_{\mathrm{a}}\right)$ and its confidence interval of $95 \%$ (95\% CI) were used to interpret the results. If the $95 \% \mathrm{CI}$ contained 1 , there was no significant difference. If the $\mathrm{OR}_{\mathrm{a}}$ was $>1$ or $<1$, the dependent variable was statistically more or less frequent in 1 group. The more $\mathrm{OR}_{\mathrm{a}}$ value was remote from 1 , the more the factor effect was significant. A statistical significance threshold was defined as $p<0.05$. Only significant differences were reported in the tables of resulting figures.

\section{RESULTS}

\section{Demographic and professional characteristics of healthcare workers}

Demographic and professional characteristics of respondents and non-respondents are shown in the Table 1. 
Table 1. Demographic and professional characteristics of respondent and non-respondent workers in emergency and critical care health units

\begin{tabular}{lccc}
\hline \multicolumn{1}{c}{ Variable } & $\begin{array}{c}\text { Respondents } \\
(\mathrm{N}=145)\end{array}$ & $\begin{array}{c}\text { Non-respondents } \\
(\mathrm{N}=230)\end{array}$ & $\mathrm{p}$ \\
\hline $\begin{array}{l}\text { Gender }(\%) \\
\text { female }\end{array}$ & 72.4 & 79.6 & 0.110 \\
Age (years) $(\mathrm{M} \pm \mathrm{SD})$ & $37.6 \pm 10.3$ & $40.9 \pm 10.6$ & 0.004 \\
Professional category $(\%)$ & & & \\
$\quad$ practitioners & 13.1 & 19.1 & \\
nurses & 53.1 & 45.7 & \\
nurse-assistants & 29.7 & 21.7 & \\
others paramedics & 4.1 & 13.5 & \\
\hline
\end{tabular}

$\mathrm{M}$ - mean; SD - standard deviation.

Out of 375 workers included in the study, 145 (38.7\%) responded to the questionnaire. The proportion of women in both respondent and non-respondent groups is similar. The mean age of all respondents was significantly lower in the respondent group than in the non-respondent group. There is a significant number of nurses and aides represented in the respondent group.

\section{Factors associated with the job strain}

The Table 2 shows the demographic and professional characteristics of the workers according to their status with respect to the JS. Out of 145 workers responding to the survey, $59.3 \%$ of them are experiencing the JS. Almost $1 / 2$ of them are nurses and more than $1 / 3$ are aides.

Organizational factors associated with the JS are shown in the Table 3. Over $80 \%$ of staff who worked more than 2 weekends per month had the JS $\left(\mathrm{OR}_{\mathrm{a}}=3.94\right)$ as well as those who were regularly on-call $\left(\mathrm{OR}_{\mathrm{a}}=2.83\right)$. Over $70 \%$ considered their workplaces dysfunctional $\left(\mathrm{OR}_{\mathrm{a}}=3.02\right)$ and more than $1 / 2$ did not participate in regular work meetings. There was a significant difference noted when the work organization facilitated

Table 2. Socio-professional and working condition characteristics in the emergency and critical care services for job strained and non-job strained health workers

\begin{tabular}{lccc}
\hline \multirow{2}{*}{ Variable } & \multicolumn{2}{c}{ Respondents } & p \\
\cline { 2 - 3 } & $\begin{array}{r}\text { job strain } \\
(\mathrm{N}=86)\end{array}$ & $\begin{array}{c}\text { no job strain } \\
(\mathrm{N}=48)\end{array}$ & $<0.001$ \\
\hline $\begin{array}{l}\text { Gender }(\%) \\
\quad \text { female }\end{array}$ & 80.2 & 50.0 & 0.018 \\
Age (years) $(\mathrm{M} \pm \mathrm{SD})$ & $35.0 \pm 9.61$ & $39.4 \pm 10.8$ & 0.006 \\
Professional category $(\%)$ & & & \\
$\quad$ practitioners & 7.0 & 25.0 & \\
nurses & 48.8 & 45.8 & \\
nurse-assistants & 38.4 & 18.8 & \\
$\quad$ others paramedics & 5.8 & 10.4 & \\
\hline
\end{tabular}

Abbreviations as in Table 1. 
Table 3. Job strain according to organizational factors

\begin{tabular}{|c|c|c|c|c|c|}
\hline \multirow[b]{2}{*}{ Variable } & \multicolumn{2}{|c|}{ Respondents } & \multirow[b]{2}{*}{$\mathrm{OR}_{\mathrm{a}}$} & \multirow[b]{2}{*}{$95 \% \mathrm{CI}$} & \multirow[b]{2}{*}{$\mathrm{p}$} \\
\hline & $\begin{array}{c}\text { job strain } \\
(\mathrm{N}=86)\end{array}$ & $\begin{array}{c}\text { no job strain } \\
\text { (reference) } \\
(\mathrm{N}=48)\end{array}$ & & & \\
\hline Worked $>2$ weekends/month $(\%)$ & 81.3 & 55.3 & 3.94 & $1.73-8.97$ & 0.001 \\
\hline Dysfunctional premises $(\%)$ & 74.1 & 46.8 & 3.02 & $1.31-6.95$ & 0.010 \\
\hline Regularly on-call (\%) & 84.1 & 55.3 & 2.83 & $1.04-7.70$ & 0.042 \\
\hline No regular meetings (\%) & 53.5 & 28.3 & 2.40 & $1.01-5.68$ & 0.047 \\
\hline $\begin{array}{l}\text { Organization not favoring } \\
\text { communication }(\mathrm{M} \pm \mathrm{SD})\end{array}$ & $9.54 \pm 2.10$ & $8.25 \pm 1.76$ & 1.49 & $1.13-1.96$ & 0.004 \\
\hline Inadequate staffing $(\mathrm{M} \pm \mathrm{SD})$ & $10.8 \pm 2.93$ & $8.68 \pm 2.69$ & 1.32 & $1.12-1.55$ & 0.001 \\
\hline Strained unit work relationships $(\mathrm{M} \pm \mathrm{SD})$ & $8.25 \pm 2.12$ & $6.97 \pm 1.86$ & 1.31 & $1.05-1.64$ & 0.017 \\
\hline
\end{tabular}

$\mathrm{OR}_{\mathrm{a}}$ - adjusted odds ratio, controlling for factors from Table 2.

$\mathrm{CI}$ - confidence interval.

Other abbreviations as in Table 1.

communications, provided adequate staffing numbers and promoted sound relationships within the healthcare team. However, there is no significant difference in fulltime work, night shifts, fluctuating schedules, knowledge or schedule overruns.

\section{Factors associated with the mental quality of life}

The Table 4 represents demographic and professional characteristics according to the participants' mental component summary (MCS). Respondents with a low MCS (54.5\%) are mostly women who are older than those having a higher MCS. No significant difference was observed in the professional categories.

Organizational factors associated with the MCS are presented in the Table 5. There is an association between the MQL and workplace functionality. Generally, workers with a low MCSs viewed their workplace as being dysfunctional $\left(\mathrm{OR}_{\mathrm{a}}=2.58\right)$. There were also significant differences between the 2 groups regarding whether or not the organization had good communications and adequate staffing. However, no significant difference was observed regarding on-call or overrun schedules or night work.

Table 4. Comparisons of low and high mental component summary (MCS) scores in emergency and critical care working conditions

\begin{tabular}{|c|c|c|c|}
\hline \multirow[b]{2}{*}{ Variable } & \multicolumn{2}{|c|}{ Respondents } & \multirow[b]{2}{*}{$\mathrm{p}$} \\
\hline & $\begin{array}{l}\text { MCS low } \\
(\mathrm{N}=79)\end{array}$ & $\begin{array}{c}\text { MCS high } \\
(\mathrm{N}=64)\end{array}$ & \\
\hline \multicolumn{4}{|l|}{ Gender (\%) } \\
\hline female & 78.5 & 60.9 & 0.022 \\
\hline Age (years) $(\mathrm{M} \pm \mathrm{SD})$ & $37.7 \pm 10.1$ & $34.8 \pm 10.5$ & 0.018 \\
\hline Leisure activities $^{\mathrm{a}}(\%)$ & & & 0.051 \\
\hline occasionally & 42.3 & 26.6 & \\
\hline regularly & 57.7 & 73.4 & \\
\hline
\end{tabular}


Table 4. Comparisons of low and high mental component summary (MCS) scores in emergency and critical care working conditions - cont.

\begin{tabular}{|c|c|c|c|}
\hline \multirow[b]{2}{*}{ Variable } & \multicolumn{2}{|c|}{ Respondents } & \multirow[b]{2}{*}{$\mathrm{p}$} \\
\hline & $\begin{array}{l}\text { MCS low } \\
(\mathrm{N}=79)\end{array}$ & $\begin{array}{c}\text { MCS high } \\
(\mathrm{N}=64)\end{array}$ & \\
\hline Alcohol consumption (\%) & & & 0.056 \\
\hline never & 34.2 & 18.8 & \\
\hline occasionally & 64.6 & 75.0 & \\
\hline everyday & 1.3 & 6.2 & \\
\hline Psychotropic consumption $(\%)$ & & & $<0.001$ \\
\hline never & 63.6 & 92.2 & \\
\hline occasionally & 26.0 & 6.2 & \\
\hline everyday & 10.4 & 1.6 & \\
\hline
\end{tabular}

Missing values: $\mathrm{a}=1, \mathrm{~b}=2$.

Abbreviations as in Table 1.

Table 5. Mental component summary (MCS) according to organizational factors

\begin{tabular}{|c|c|c|c|c|c|}
\hline \multirow[b]{2}{*}{ Variable } & \multicolumn{2}{|c|}{ Respondents } & \multirow[b]{2}{*}{$\mathrm{OR}_{\mathrm{a}}$} & \multirow[b]{2}{*}{$95 \% \mathrm{CI}$} & \multirow[b]{2}{*}{$\mathrm{p}$} \\
\hline & $\begin{array}{l}\text { MCS low } \\
(\mathrm{N}=79)\end{array}$ & $\begin{array}{l}\text { MCS high } \\
\text { (reference) } \\
(\mathrm{N}=64)\end{array}$ & & & \\
\hline Dysfunctional premises (\%) & 76.4 & 54.7 & 2.58 & $1.15-5.79$ & 0.022 \\
\hline $\begin{array}{l}\text { Organization not favoring } \\
\text { communication }(\mathrm{M} \pm \mathrm{SD})\end{array}$ & $9.72 \pm 1.93$ & $8.54 \pm 1.95$ & 1.46 & $1.15-1.87$ & 0.002 \\
\hline Inadequate staffing $\mathrm{m}(\sigma)$ & $11.0(2.86)$ & $9.19(2.81)$ & 1.31 & $1.13-1.52$ & $<0.001$ \\
\hline
\end{tabular}

* OR controlling for factors from Table 4.

Abbreviations as in Table 1 and 3.

\section{DISCUSSION}

Only significant results have been discussed here. The 2 first sections have dealt with data of the JS and the 2 following with data of the MQL.

In this study, the proportion of subjects having the JS (59.3\%) is much higher than those of the French general population (23\%) [20] and those of nurses studied in Sweden, Canada, or China [29-31]. This high rate can be explained by the hospital work environment [32]. The need to intervene at short notice, take care of serious illnesses or be faced with aggression by patients or their families all provoke high levels of job stress [15].
In our study, women with the JS (80.2\%) represented higher figures than the French general population (51.5\%). Women report higher psychological demands than men [24]. In a recent study conducted with Chinese nurses [2], the average age of workers experiencing the JS is lower (35 years) than those not experiencing the JS (39.4 years). The 2003 study of French hospitals [33] showed that staff's perception of working conditions varied according to age. Older staff state they feel less exposed to hardship and, to a lesser extent, have a higher ability to manage work challenges than younger staff. This may be contributed to the perspective that more work experience connotes 
increased confidence. However, the high fluctuation of staff in intensive care and emergency units [20] suggests that older staff is best suited to these working conditions. The risk of having the JS also varied according to the professional category.

In our study, nurses and aides are significantly more stressed than the other paramedics and doctors. If the psychological demand is high for most of the staff working in emergency departments or intensive care units, it has been shown that nurses perceive a greater mental burden than aides or paramedical professions [33].

Work organization plays an important role in developing the JS. The results of this study indicate that employees working at least 2 weekends a month are much tenser than others $\left(\mathrm{OR}_{\mathrm{a}}=3.94\right)$ and more than $80 \%$ of employees who regularly work on-call are job strained $\left(\mathrm{OR}_{\mathrm{a}}=2.83\right)$. Previous studies have demonstrated a strong association between the number of hours worked per week and the JS [20]. According to our results, the JS is attributable to inadequate rest periods between shifts rather than working hours that are not known in advance. Flexible schedules, schedule overruns, etc., do not seem to have any influence on the JS.

Our study indicates that the JS is related to inadequate staffing levels. The past years' decline and disrepair of French hospitals could be an explanation for increased workloads and psychological demands on staff. Staff shortages have resulted in demands for consecutive weekends of work or regular on-call scheduling. The strong association between the JS, weekend work and on-call scheduling can also explain the difficulty of reconciling work, biological rhythms and life outside work. In addition, the JS was associated with a decrease in leisure time or physical activity [34].

More than $2 / 3$ of the JS is related to dysfunctional work environments. This is higher than the 2003 study on all French hospital staff where $49 \%$ of emergency and intensive care staff considered their work environment dysfunctional [35]. The physical environment (noise and heat) and technical (design and ergonomics) of workplaces is indeed known to be a major cause of occupational stress.

Communication problems linked to the services' organization or lack of regular meetings and discordant staff relationships influence the JS as well. A link between intensive care physicians with symptoms of depression and the quality of professional relationships has been shown in a previous study [36]. Collegial conflicts are associated with high levels of job stress [21].

A survey in Switzerland showed that good work-place relationships is the main expectation of the interviewed physicians [22]. Lack of communication, or lack of support from superiors, also increases the risk of the JS. Some participatory management, whether it is authoritarian or deficient, and a lack of performance recognition increases work tensions for employees.

In our study, the focus is not only on the poor relations between key staff involved, but also on those organizations that thwart communications. A fairly strong relationship between the JS and a lack of regular meetings was observed. Hospital economic and organizational constraints have caused a reduction of overlap time which had allowed teams to exchange information and to debate staff's challenges and needs.

The literature data indicates over $60 \%$ of emergency and intensive caregivers who are not satisfied with the amount of overlap time, and $65.1 \%$ of them believe that they cannot discuss organizational issues in detail [19]. Communication within teams is nevertheless crucial for optimal patient management [22].

In our study population, a low MQL is observed in 54.5\% of workers. Although health care workers are known to have a poor quality of life [37], to the best of our knowledge there is no specific MQL study on emergency and intensive care hospital staff. Women have the lowest MQL, which is also reflected in the French general 
population [38]. Numerous epidemiological studies have shown that women have a higher prevalence of psychological morbidity than men [3,39].

Unlike a previous study [2] on nurses in a military hospital in Taiwan, the MQL is poorer in the case of older workers. This could be explained by the difficulty in emergency and intensive care units in staffing their positions with older personnel. The professional category in this study does not seem to influence the workers' quality of life, which is contrary to the results of a previous study showing that nurses had poorer MQL than other health professionals [40]. There is a relationship established between the MQL and lifestyle demonstrating that personnel with regular leisure activities are significantly more likely to have a better MQL.

These results are also consistent with a recent Brazilian study [41]. Psychotropic drug use increases with job stress and personnel with high drug consumption are also those with a poor quality of life [10]. Our study confirms these findings.

Emergency and intensive care staff's MQL is directly influenced by the institution's organizational model. Our study indicates that more than $2 / 3$ of those with a low MCS considers their work environment to be dysfunctional $\left(\mathrm{OR}_{\mathrm{a}}=2.58\right)$. A poor organizational model with weak inter-staff communications is directly related to staff's poor MQL scores.

It appears that better organization of work schedules with adequate rest periods and a regular practice of leisure activities improve the professional well-being of hospital staff. The recent implementation of 12-h shifts seems to support this [42]. The development of functional, ergonomic and adapted work environments could also contribute to the reduction of occupational stress in hospitals. Doctors' and nurses' perceptions regarding relationships between different health care workers are dissimilar. Doctors seem to be more satisfied with the doctor-nurse communications and collaborations than nurses do [43].
Improved communications can be achieved by means of simple solutions such as regular staff meetings to delineate staff's roles as well as to clarify and obtain endorsement of operating policies. Participation of staff from all occupational categories appears beneficial. There also needs to be sufficient time for health care teams to transfer patient information to ensure continuity of care in optimal conditions. The support team leaders can be very effective regulators since they are perceived by employees as indicators of stress (anxiety, depression, dissatisfaction) [44].

Finally, staff integration in decision-making enhances their autonomy and investment in their work. Job satisfaction, which plays a major role in the professionals' health and quality of life, could thus be improved and, by extension, contribute to the quality of care received by patients. Our study has some limitations such as the high non-response rate which produces the information bias. Nurses and aides, who had the highest JS scores and work in professionally tense situations, appear more sensitive to the goals of our study and therefore had the highest response rate to our questionnaire. Non-respondents were about the same age as not job-strained workers. It is highly likely that the sample of participants represents the more motivated individuals experiencing job strain, and thus, might overestimate the percentage of staff members with the JS in the population. The single-center nature of the study limits result generalizations to other types of health facilities such as health centers and clinics, since these have different organizational models. Moreover, there is no currently validated questionnaire on psychoorganizational constraints for doctors.

\section{CONCLUSIONS}

To our knowledge, our study is the 1st one to analyze if organizational models have an impact upon the MQL of emergency and intensive care staff. In addition, this investigation quantifies the strength of association between the JS and the various factors identified 
in the study, thereby enabling the management to implement logical, preventive strategies regarding the quality of work-life and quality of care.

In emergency and intensive care units, ergonomic environment and communication are 2 main qualities of work life determinants. Moreover, hospital management needs to provide a better balance between working and non-working hours.

\section{ACKNOWLEDGMENTS}

We would like to thank the study participants as well as Monique Douroux, Lucie Mérigot and Julia Sportiello for their assistance.

\section{REFERENCES}

1. Karasek RA. Job demands, job decision latitude, and mental strain: Implications for job redesign. Admin Sci Quart.1979;24(2):285-308,http://dx.doi.org/10.2307/2392498.

2. Tzeng DS, Chung WC, Yang CY. The effect of job strain on psychological morbidity and quality of life in military hospital nurses in Taiwan: A follow-up study. Ind Health. 2013;51(4):443-51, http://dx.doi.org/10.2486/indhealth.2012-0013.

3. Niedhammer I, Chastang JF, David S, Barouhiel L, Barrandon G. Psychosocial work environment and mental health: Job-strain and effort-reward imbalance models in a context of major organizational changes. Int J Occup Environ Health 2006;12(2):111-9, http://dx.doi.org/10.1179/ oeh.2006.12.2.111.

4. Head J, Kivimäki M, Martikainen P, Vahtera J, Ferrie JE, Marmot MG. Influence of change in psychosocial work characteristics on sickness absence: The Whitehall II Study. J Epidemiol Community Health. 2006;60(1):55-61, http:// dx.doi.org/10.1136/jech.2005.038752.

5. De Croon EM, Sluiter JK, Blonk RW, Broersen JP, FringsDresen MH. Stressful work, psychological job strain, and turnover: A 2-year prospective cohort study of truck drivers. J Appl Psychol. 2004;89(3):442-54, http://dx.doi. org/10.1037/0021-9010.89.3.442.
6. Kalia M. Assessing the economic impact of stress. The modern day hidden epidemic. Metabolism. 2002 Jun;51(6 Suppl 1):49-53, http://dx.doi.org/10.1053/meta.2002.33193.

7. Medibank Private. The cost of workplace stress in Australia. 2008 [cited 2013 Mar 5]. Available from: http://www. medibank.com.au/Client/Documents/Pdfs/The-Cost-ofWorkplace-Stress.pdf.

8. Trontin C, Lassagne M, Boini S, Rinal S. [The cost of the professional stress in France in 2007]. INRS; 2009 [cited 2013 Mar 5]. Available from: http://www.inrs.fr/ accueil/dms/inrs/PDF/cout-stress-professionnel2007.pdf. French.

9. Peterson U, Demerouti E, Bergström G, Samuelsson M, Asberg M, Nygren A. Burnout and physical and mental health among Swedish healthcare workers. J Adv Nurs. 2008;62(1):84-95, http://dx.doi.org/10.1111/j.13652648.2007.04580.x.

10. Estryn-Behar M, Kaminski M, Peigne E, Bonnet N, Vaichere E, Gozlan C, et al. Stress at work and mental health status among female hospital workers. Br J Ind Med. 1990;47(1):20-8.

11. Alpert JS. Physician depression. Am J Med. 2008; 121(8):643, http://dx.doi.org/10.1016/j.amjmed.2008.01.013.

12. Firth-Cozens J. Doctors, their wellbeing, and their stress: It's time to be protective about stress and prevent it (editorials). BMJ. 2003;326:670, http://dx.doi.org/10.1136/bmj. 326.7391 .670 .

13. McGrath A, Reid N, Boore J. Occupational stress in nursing. Int J Nurs Stud. 2003;40(5):555-65, http://dx.doi. org/10.1016/S0020-7489(03)00058-0.

14. Donchin Y, Seagull FJ. The hostile environment of the intensive care unit. Curr Opin Crit Care. 2002;8(4):316-20, http://dx.doi.org/10.1097/00075198-200208000-00008.

15. Healy S, Tyrrell M. Stress in emergency departments: Experiences of nurses and doctors. Emerg Nurse. 2011;19 (4):31-7, http://dx.doi.org/10.7748/en2011.07.19.4.31.c8611.

16. Coomber S, Todd C, Park G, Baxter P, Firth-Cozens J, Shore S. Stress in UK intensive care unit doctors. 
Br J Anaesth. 2002;89(6):873-81, http://dx.doi.org/10.1093/ bja/aef273.

17. Poncet MC, Toullic P, Papazian L, Kentish-Barnes N, Timsit JF, Pochard F, et al. Burnout syndrome in critical care nursing staff. Am J Respir Crit Care Med. 2007;175(7): 698-704.

18. Hooper C, Craig J, Janvrin DR, Wetsel MA, Reimels E. Compassion satisfaction, burnout, and compassion fatigue among emergency nurses compared with nurses in other selected inpatient specialties. J Emerg Nurs. 2010 Sep;36(5):420-7, http://dx.doi.org/10.1016/j.jen.2009.11.027.

19. Estryn-Behar M, Ben-Brik E, Le Nezet O, Affre A, Arbieu P, Bedel M, et al. [The situation of caregivers of public and private institutions in France in 2002: Analysis of the results of the first part of the study PRESST-NEXT]. Arch Mal Prof Env. 2004;65(5):413-37, http://dx.doi.org/10.1016/ S1775-8785(04)93483-2. French.

20. Cartledge S. Factors influencing the turnover of intensive care nurses. Intensive Crit Care Nurs. 2001 Dec;17(6):34855, http://dx.doi.org/10.1054/iccn.2001.1599.

21. Biaggi P, Peter S, Ulich E. Stressors, emotional exhaustion and aversion to patients in residents and chief residents - What can be done? Swiss Med Wkly. 2003;133(23-24):339-46.

22. Reader TW, Flin R, Mearns K, Cuthbertson BH. Developing a team performance framework for the intensive care unit. Crit Care Med. 2009 May;37(5):1787-93, http://dx.doi. org/10.1097/CCM.0b013e31819f0451.

23. Bonneterre V, Ehlinger V, Balducci F, Caroly S, Jolivet A, Sobaszek A, et al. ORSOSA group. Validation of an instrument for measuring psychosocial and organizational work constraints detrimental to health among hospital workers: The NWI-EO questionnaire. Int J Nurs Stud. 2011;48(5):557-67.

24. Guignon N, Sandret N. [Psychosocial factors at work. An evaluation by the Karasek questionnaire survey in Sumer 2003]. No22.1. DARES; 2008. French.

25. Niedhammer I, Chastang J-F, Gendrey D, David S, Degioanni S. [Psychometric properties of the French version of Karasek's "Job Content Questionnaire" and its scales measuring psychological pressures, decisional latitude and social support: The results of the SUMER]. Santé Publique. 2006;18(3):413-427, http://dx.doi.org/10.3917/ spub.063.0413. French.

26. Gandek B, Ware JE, Aaronson NK, Apolone G, Bjomer JB, Brazier JE, et al. Cross-validation of item selection and scoring for the SF-12 Health Survey in 9 countries: Results from the IQOLA Project. J Clin Epidemiol. 1998;51(11): 1171-8, http://dx.doi.org/10.1016/S0895-4356(98)00109-7.

27. Karasek RA, Brisson C, Kawakami N, Houtman I, Bongers P, Amick B. The Job Content Questionnaire (JCQ): An instrument for internationally comparative assessments of psychological job characteristics. J Occup Health Psychol. 1998;3(4):322-55, http://dx.doi.org/10.1037/10768998.3.4.322.

28. Lang T, Delpierre C. [Health, self-rated "objectified" health and social categories. Secondary analysis of the INSEE decadal survey 2003]. Unité Mixe de Recherche 558. 114 p. ING36. French.

29. Josephson M, Lagerström M, Hagberg M, Wigaeus Hjelm E. Musculoskeletal symptoms and job strain among nursing personnel: A study over a 3 year period. Occup Environ Med. 1997;54(9):681-5, http://dx.doi.org/10.1136/ oem.54.9.681.

30. Bourbonnais R, Comeau M, Vézina M. Job strain and evolution of mental health among nurses. J Occup Health Psychol. 1999 Apr;4(2):95-107.

31. Chien TW, Lai WP, Wang HY, Hsu SY, Castillo RV, Guo HR, et al. Applying the revised Chinese Job Content Questionnaire to assess psychosocial work conditions among Taiwan's hospital workers. BMC Public Health. 2011;11:478, http://dx.doi.org/10.1186/1471-2458-11-478.

32. Cronin-Stubbs D, Rooks CA. The stress, social support and burnout of critical care nurses: The results of research. Heart Lung. 1985;14(1):31-9.

33. Dumas A, Le Lan R. [Age and working conditions in health facilities. Social Data in French society]. 2006 [cited 2013 
Feb 2]. Available from: http://www.insee.fr/fr/ffc/docs_ffc/ donsoc06ys.pdf. French.

34. Fransson E, Heikkliä K, Nyberg S, Zins M, Westerlund H, Westerholm P. Job strain as a risk factor for leisure-time physical inactivity: An individual-participant meta-analysis of up to 170,000 men and women. Am J Epidemiol. 2012;176(12):1078-89, http://dx.doi.org/10.1093/aje/kws336.

35. Embriaco N, Hraiech S, Azoulay E, Baumstarck-Barrau K, Forel JM, Kentish-Barnes N, et al. Symptoms of depression in ICU physicians. Ann Intensive Care. 2012;2(1):34, http:// dx.doi.org/10.1186/2110-5820-2-34 .

36. Embriaco N, Azoulay E, Barrau K, Kentish N, Pochard F, Loundou A, et al. High level of burnout in intensivists: Prevalence and associated factors. Am J Respir Crit Care Med. 2007;175(7):686-92, http://dx.doi.org/10.1164/rccm. 200608-11840C.

37. He M, Wang Q, Zhu S, Tan A, He Q, Chen T, et al. Healthrelated quality of life of doctors and nurses in China: Findings based on the latest open-access data. Qual Life Res. 2012; 21(10):1727-30, http://dx.doi.org/10.1007/s11136-011-0088-0.

38. Albouy V, Duée M, Godefroy P. [Quality of life for men and women. Looks on parity]. Insee Références: Édition 2012 [cited 2013 Feb 2]. Available from: http://www.insee.fr/fr/ffc/ docs_ffc/ref/FHPARIT12d_VE3quali.pdf. French.

39. Waldenström K, Lundberg I, Waldenström M, Härenstam A; MOA Research Group. Does psychological distress influence reporting of demands and control at work? Occup Environ Med. 2003;60(11):887-91, http://dx.doi.org/10.1136/ oem.60.11.887.

40. Silva AA, Pacheco de Souza JM, da Silva Borges FN, Fischer FM. Health-related quality of life and working conditions among nursing providers. Rev Saude Publica. 2010;44(4):718-25, http://dx.doi.org/10.1590/S0034-891 02010000400016.

41. Torres A, Ruiz T, Müller S, Pereira Lima MC. Quality of life, physical and mental heath of physicians: A self-evaluation by graduates from Botucatu Medical School - UNESP. Rev Bras Epidemiol. 2011;14(2):264-75, http://dx.doi. org/10.1590/S1415-790X2011000200008.

42. Richardson A, Turnock C, Harris L, Finley A, Carson S. A study examining the impact of 12-hour shifts on critical care staff. J Nurs Manag. 2007 Nov;15(8):838-46, http:// dx.doi.org/10.1111/j.1365-2934.2007.00767.x.

43. Thomas EJ, Sexton JB, Helmreich RL. Discrepant attitudes about teamwork among critical care nurses and physicians. Crit Care Med. 2003;31(3):956-9, http://dx.doi. org/10.1097/01.CCM.0000056183.89175.76.

44. Aiken LH, Clarke SP, Sloane DM; International Hospital Outcomes Research Consortium. Hospital staffing, organization, and quality of care: Cross-national findings. Int J Qual Health Care. 2002;14(1):5-13, http://dx.doi. org/10.1093/intqhc/14.1.5.

This work is available in Open Access model and licensed under a Creative Commons Attribution-NonCommercial 3.0 Poland License - http://creativecommons.org/ licenses/by-nc/3.0/pl/deed.en. 